\title{
Papers
}

\section{Alcohol estimation at necropsy: epidemiology, economics, and the elderly}

\author{
Diana E Cox, David W Sadler, Derrick J Pounder
}

\begin{abstract}
Aims-To gather data on blood alcohol concentrations in a forensic necropsy population and to analyse the information on trends that may predict where alcohol testing is going to prove cost-effective.

Methods-Alcohol assays were performed on blood, urine, and vitreous samples in 1620 consecutive medicolegal necropsy examinations.

Results-Alcohol was detected in only $7 \%$ of natural deaths from all causes and in four of $\mathbf{4 0}$ deaths categorised as unknown/ obscure. Alcohol concentrations $\geq 350$ $\mathrm{mg} / 100 \mathrm{ml}$ were found in nine drug/alcohol abuse deaths (range $362-506 \mathrm{mg} / 100 \mathrm{ml}$ ), five accidental deaths (356-504 $\mathrm{mg} / 100$ $\mathrm{ml}$ ), and one homicide victim (400 mg/100 $\mathrm{ml}$ ). Those categorised as alcohol abusers were represented in all but one category of death (unknown/obscure deaths in males), showing that many true alcoholics die with their alcoholism rather than of it; $39 \%$ of males and $34 \%$ of females with histories of alcohol abuse had alcohol present in their blood at necropsy at concentrations $\geq 50 \mathrm{mg} / 100 \mathrm{ml}, v$ only $9 \%$ (male) and $6 \%$ (female) without such history.

Conclusions-The study highlights the problems of elderly and "hidden" alcoholics and illustrates cases where routine assays would provide additional significant information. Routine alcohol testing is useful in all cases of suspected unnatural death but universal testing of forensic necropsies is not cost-effective. $(\mathcal{C}$ Clin Pathol 1997;50:197-201)
\end{abstract}

Keywords: alcohol estimation; necropsy; economics; elderly.

Department of

Forensic Medicine,

University of Dundee,

Dundee

D W Sadler

D J Pounder

Correspondence to: Dr Diana E Cox, The London Medicolegal Centre, 40 Stockwell Street,

Greenwich, London SE10 $8 \mathrm{EY}$.

Accepted for publication 4 December 1996

Research on the presence and concentration of alcohol at medicolegal necropsy has not been performed in the United Kingdom, although two studies have been conducted in continental Europe. ${ }^{12}$ Drinking patterns vary from country to country, so these data may not be applicable to the British forensic necropsy population. We investigated the prevalence of alcohol in the blood at death, the circumstances likely to result in the presence of alcohol in necropsy specimens, and the economic considerations of routine testing. Given the dual concerns of the preponderance of elderly people in the forensic necropsy population and the issue of alcohol abuse in the elderly, ${ }^{3}$ we also specifically addressed these topics. This study provides basic data to inform discussion of the issues raised.

\section{Methods}

Alcohol assays were performed on blood, urine, and vitreous samples, where available, on 1730 consecutive medicolegal necropsies (1071 full necropsy examinations and 549 external examinations) performed between 9 April 1990 and 2 April 1993, comprising all medicolegal necropsy examinations in Tayside and North East Fife with additional cases (homicide and anaesthetic/medical related deaths) from outside these regions. Relevant data from case files, including police reports, general practitioner records, and hospital records were abstracted, namely sex, age, analytical results, cause of death, manner of death, alcohol habits, agonal hospital admission, and any pertinent comments such as other positive toxicology. Overall, 1620 cases were included; 110 cases were excluded as no sample was taken because of HIV or hepatitis B risk (29), decomposition (36), exsanguination (14), cot death (5), and prolonged hospital admission or other practical reasons (23).

Blood samples were collected under direct vision from the femoral vein in cases of full necropsy and from the subclavian vessels by blind needle puncture in external examinations. Urine was collected directly from the bladder in necropsies and by blind suprapubic aspiration in external examinations. Blood samples were stored in fluoride oxalate tubes, vitreous in one dram $(3.7 \mathrm{ml})$ vials, and urine were refrigerated at $4^{\circ} \mathrm{C}$ before analysis by head space gas chromatography using a previously published method. ${ }^{4}$ Samples were batched, run in duplicate, and accompanied by appropriate calibration and control specimens. Results were a mean of duplicates; analysis was repeated if the values were not within 10 $\mathrm{mg} / 100 \mathrm{ml}$. 
Table 1 Cases with blood alcohol concentrations of $\geq 50 \mathrm{mg} / 100 \mathrm{ml}(B A C+)$ by sex and category of death. Percentages relate the figures to the total deaths (positive and negative) for each sex and category

\begin{tabular}{|c|c|c|c|c|c|c|c|c|c|}
\hline \multirow[b]{3}{*}{ Manner of death } & \multicolumn{3}{|l|}{ Male } & \multicolumn{3}{|c|}{ Female } & \multicolumn{3}{|c|}{ Male and female } \\
\hline & \multirow[b]{2}{*}{ Total } & \multicolumn{2}{|l|}{$B A C+$} & \multirow[b]{2}{*}{ Total } & \multicolumn{2}{|l|}{$B A C+$} & \multirow[b]{2}{*}{ Total } & \multicolumn{2}{|l|}{$B A C+$} \\
\hline & & Number & Percentage & & Number & Percentage & & Number & Percentage \\
\hline 1 - Natural (CVS) & 514 & 26 & 5 & 305 & 8 & 3 & 819 & 34 & 4 \\
\hline 1 - Natural (other) & 121 & 3 & 2 & 106 & 3 & 3 & 227 & 6 & 3 \\
\hline 2 - Accident & 173 & 40 & 23 & 68 & 8 & 12 & 241 & 48 & 20 \\
\hline 3 - Suicide & 126 & 43 & 34 & 53 & 14 & 26 & 179 & 57 & 32 \\
\hline 4 - Homicide & 24 & 9 & 38 & 12 & 5 & 42 & 36 & 14 & 39 \\
\hline $\begin{array}{l}5 \text { - Drug or alcohol } \\
\text { abuse }\end{array}$ & 50 & 17 & 34 & 28 & 10 & 36 & 78 & 27 & 35 \\
\hline 6 - Unknown/obscure & 26 & 1 & 4 & 14 & 3 & 21 & 40 & 4 & 10 \\
\hline Total & 1034 & 139 & 13 & 586 & 51 & 9 & 1620 & 190 & 12 \\
\hline
\end{tabular}

The blood alcohol result was considered positive at a level of $\geq 50 \mathrm{mg} / 100 \mathrm{ml}$. This is the concentration chosen by some countries as the legal limit for driving. ${ }^{5}$ Published reports suggest that necropsy blood alcohol concentrations greater than $40 \mathrm{mg} / 100 \mathrm{ml}$ reflect the antemortem alcohol status of the deceased. ${ }^{6} \mathrm{An}$ individual was considered to have suffered from alcohol abuse if there was a history of chronic alcoholism, alcohol related disease, or indications of persistent or episodic excessive drinking obtained from the general practitioner, police or hospital records, and the information was elicited from more than one of these sources. Deaths were categorised by manner of death into natural (cardiovascular or other), accident, suicide, drug/alcohol related, and unknown/obscure. Drug/alcohol related deaths comprised known chronic alcoholics and drug abusers dying of their abuse and those whose deaths were attributed to the effects of alcohol, either alone or in combination with a drug or drugs, other than clear suicidal overdoses. Unknown/obscure deaths included cot deaths, "negative" necropsies, and cases where the manner of death was not classified.

Table 2 Males with blood alcohol concentrations $(B A C) \geq 50 \mathrm{mg} / 100 \mathrm{ml}$ by category and concentration

\begin{tabular}{|c|c|c|c|c|c|c|}
\hline \multirow[b]{2}{*}{ Manner of death } & \multicolumn{2}{|c|}{$B A C+$} & \multicolumn{4}{|c|}{ Alcohol concentration $(\mathrm{mg} / 100 \mathrm{ml})$} \\
\hline & Total & $\%$ & $50-149$ & $150-249$ & $250-349$ & $350+$ \\
\hline 1 - Natural (CVS) & 26 & 19 & 13 & 12 & 1 & 0 \\
\hline 1 - Natural (other) & 3 & 2 & 1 & 2 & 0 & 0 \\
\hline 2 - Accident & 40 & 29 & 14 & 13 & 9 & 4 \\
\hline 3 - Suicide & 43 & 31 & 19 & 20 & 4 & 0 \\
\hline $\begin{array}{l}4 \text { - Homicide } \\
5 \text { - Drug or alcohol }\end{array}$ & 9 & 6 & 3 & 1 & 4 & 1 \\
\hline abuse & 17 & 12 & 2 & 6 & 4 & 5 \\
\hline 6 - Unknown/obscure & 1 & 1 & 1 & 0 & 0 & 0 \\
\hline Total & 139 & 100 & 53 & 54 & 22 & 10 \\
\hline
\end{tabular}

Table 3 Females with blood alcohol concentrations (BAC) $\geq 50 \mathrm{mg} / 100 \mathrm{ml}$ by category and concentration

\begin{tabular}{|c|c|c|c|c|c|c|}
\hline \multirow[b]{2}{*}{ Manner of death } & \multicolumn{2}{|c|}{$B A C+$} & \multicolumn{4}{|c|}{ Alcohol concentration $(\mathrm{mg} / 100 \mathrm{ml}$ ) } \\
\hline & Total & $\%$ & $50-149$ & $140-249$ & $250-349$ & $350+$ \\
\hline 1 - Natural (CVS) & 8 & 16 & 5 & 1 & 2 & 0 \\
\hline 1 - Natural (other) & 3 & 6 & 2 & 1 & 0 & 0 \\
\hline 2 - Accident & 8 & 16 & 3 & 2 & 2 & 1 \\
\hline 3 - Suicide & 14 & 27 & 8 & 2 & 4 & 0 \\
\hline 4 - Homicide & 5 & 10 & 2 & 2 & 1 & 0 \\
\hline 5 - Drug or alcohol & & & & & & \\
\hline $\begin{array}{l}\text { abuse } \\
6 \text { - Unknown/obscure }\end{array}$ & 10 & 20 & 1 & 2 & 3 & 4 \\
\hline $\begin{array}{l}6 \text { - Unknown/obscure } \\
\text { Total }\end{array}$ & 3 & 6 & 0 & 3 & 0 & 0 \\
\hline Total & 51 & 100 & 21 & 13 & 12 & 5 \\
\hline
\end{tabular}

In considering the problem of corroboration of alcohol assays for very low blood alcohol concentrations a lower cut off point of 5 $\mathrm{mg} / 100 \mathrm{ml}$ was used. At levels between 5 $\mathrm{mg} / 100 \mathrm{ml}$ and $50 \mathrm{mg} / 100 \mathrm{ml}$ there may be doubt as to whether the analytical result truly reflects the antemortem status of the deceased or represents a postmortem artefact. Corroboration of the blood alcohol result by reference to an alternative sample such as urine or vitreous humour may be valuable in these circumstances.

\section{Results and discussion}

The results are presented as tables, breaking down the data according to major discriminators of sex, age, presence of alcohol, and history of alcohol abuse, further subdivided by manner of death and alcohol concentration. Table 1 lists cases having alcohol concentrations of $\geq 50$ $\mathrm{mg} / 100 \mathrm{ml}$ by sex and category of death. Tables 2 (males) and 3 (females) subdivide the cases by category and alcohol concentration. Table 4 breaks down the data by sex, presence or absence of a history of alcohol abuse, and manner of death. Table 5 lists the cases by sex, history of alcohol abuse, and the presence of alcohol in necropsy samples. It includes 10 cases where no blood sample was available but both urine and vitreous samples were taken and both contained significant quantities of alcohol. Table 6 correlates sex, alcohol consumption habits, and blood alcohol concentration. Table 7 addresses alcohol concentrations in the elderly population. Tables 8 and 9 consider alternative samples for detecting alcohol in the body at levels between 11 and 50 $\mathrm{mg} / 100 \mathrm{ml}$ and the corroboration of blood alcohol levels in this low range by reference to alternative samples.

This is the first systematic study of blood alcohol concentrations in a forensic necropsy population in the United Kingdom. Similar studies have been performed in Finland ${ }^{1}$ and Germany. ${ }^{2}$

The incidence of alcohol positivity (table 1) was highest for both sexes combined in homicides (39\%), followed by drug/alcohol related deaths $(35 \%)$, suicides $(32 \%)$, and accidents $(20 \%)$. Males accounted for greater percentages for suicides $(34 \% \mathrm{M}, 26 \% \mathrm{~F})$ and accidents $(23 \% \mathrm{M}, 12 \% \mathrm{~F})$. Alcohol was detected in only $7 \%$ of natural deaths from all causes. In four of 40 deaths categorised as 
Table 4 Incidence of positive history $(H)$ of alcohol abuse for each sex and by category of death

\begin{tabular}{|c|c|c|c|c|c|c|c|c|c|c|c|c|c|c|c|}
\hline \multirow{3}{*}{$\begin{array}{l}\text { Manner of } \\
\text { death }\end{array}$} & \multicolumn{5}{|l|}{ Male } & \multicolumn{5}{|c|}{ Female } & \multicolumn{5}{|c|}{ Male and female } \\
\hline & \multirow[b]{2}{*}{ Total } & \multicolumn{2}{|c|}{ Number } & \multicolumn{2}{|c|}{ Percent } & \multirow[b]{2}{*}{ Total } & \multicolumn{2}{|c|}{ Number } & \multicolumn{2}{|c|}{ Percent } & \multirow[b]{2}{*}{ Total } & \multicolumn{2}{|c|}{ Number } & \multicolumn{2}{|c|}{ Percent } \\
\hline & & $\mathrm{H}^{+}$ & $H_{-}$ & $\mathrm{H+}$ & $H_{-}$ & & $H+$ & $H^{-}$ & $H^{+}$ & $H^{-}$ & & $H^{+}$ & $H^{-}$ & $H^{+}$ & $H^{-}$ \\
\hline $\begin{array}{l}1 \text { - Natural } \\
\text { (CVS) } \\
1 \text { - Natural }\end{array}$ & 514 & 48 & 466 & 9 & 91 & 305 & 17 & 288 & 6 & 94 & 819 & 65 & 754 & 8 & 92 \\
\hline (other & 121 & 20 & 101 & 17 & 83 & 106 & 6 & 100 & 6 & 94 & 227 & 26 & 201 & 11 & 89 \\
\hline 2 - Accident & 173 & 18 & 155 & 10 & 90 & 68 & 4 & 64 & 6 & 94 & 241 & 22 & 219 & 9 & 91 \\
\hline 3 -Suicide & 126 & 28 & 96 & 22 & 78 & 53 & 10 & 43 & 19 & 81 & 179 & 38 & 141 & 21 & 79 \\
\hline 4 - Homicide & 24 & 3 & 21 & 13 & 88 & 12 & 1 & 11 & 8 & 92 & 36 & 4 & 32 & 11 & 89 \\
\hline $\begin{array}{l}5 \text { - Drug or } \\
\text { alcohol }\end{array}$ & & & & & & & & & & & & & & & \\
\hline & 50 & 41 & 9 & 82 & 18 & 28 & 22 & 6 & 79 & 21 & 78 & 63 & 15 & 81 & 19 \\
\hline obscure & 26 & 0 & 26 & 0 & 100 & 14 & 2 & 12 & 14 & 86 & 40 & 2 & 38 & 5 & 95 \\
\hline Total & 1034 & 158 & 876 & 15 & 85 & 586 & 62 & 524 & 11 & 89 & 1620 & 220 & 1400 & 14 & 86 \\
\hline
\end{tabular}

unknown/obscure, one male who fell or jumped from a cliff had an alcohol concentration of $133 \mathrm{mg} / 100 \mathrm{ml}$ and three females with no anatomical cause of death had concentrations of 168,190 , and $238 \mathrm{mg} / 100 \mathrm{ml}$ (tables 2 and 3). Two of these had histories suggestive of excess alcohol consumption from one source only, of a nature which did not clearly indicate regular or periodic alcohol abuse.

Alcohol concentrations $\geq 350 \mathrm{mg} / 100 \mathrm{ml}$ (both sexes) were found in nine drug/alcohol abuse deaths (range $362-506 \mathrm{mg} / 100 \mathrm{ml}$ ), five accidental deaths (range 356-504 mg/100 ml), and one homicide victim who had a level of 400 $\mathrm{mg} / 100 \mathrm{ml}$ (tables 2 and 3). Generally, there were decreasing numbers of deaths at higher alcohol concentrations for both sexes, with the exception of alcohol/drug related deaths. The trends for females were similar to males despite there being fewer cases $(1034 \mathrm{M}, 586 \mathrm{~F})$. Breakdown of the data by sex, age group, and cause of death did not show any clear trends in this series.

Breakdown by a history of alcohol abuse (table 4) showed that those whose deaths were attributed to the effects of alcohol were at least three times more likely to have a positive alcohol history than not. However, this probably reflected the use of the history in reaching the

Table 5 Presence or absence of alcohol by sex and history of alcohol abuse

\begin{tabular}{|c|c|c|c|c|c|c|c|}
\hline \multirow[b]{2}{*}{$\begin{array}{l}\text { Sex, alcohol } \\
\text { history }\end{array}$} & \multirow[b]{2}{*}{ Total } & \multicolumn{3}{|c|}{ Number } & \multicolumn{3}{|c|}{ Percentage } \\
\hline & & $B A C-$ & $\begin{array}{l}\text { No blood }(U+ \\
\text { andlor } V+)\end{array}$ & $B A C+$ & $B A C-$ & $\begin{array}{l}\text { No blood (U+ } \\
\text { andlor } V+)\end{array}$ & $B A C+$ \\
\hline$\overline{\mathrm{M}, \mathrm{H}+}$ & 158 & 97 & 0 & 61 & 61 & 0 & 39 \\
\hline $\mathrm{M}, \mathrm{H}-$ & 876 & 792 & 5 & 79 & 90 & 1 & 9 \\
\hline $\mathrm{F}, \mathrm{H}+$ & 62 & 40 & 1 & 21 & 64 & 2 & 34 \\
\hline $\mathrm{F}, \mathrm{H}-$ & 524 & 490 & 4 & 30 & 93 & 1 & 6 \\
\hline Total & 1620 & 1419 & 10 & 191 & 87 & 1 & 12 \\
\hline
\end{tabular}

$\mathrm{BAC}=$ blood alcohol concentration; $\mathrm{U}=$ urine; $\mathrm{V}=$ vitreous; $\mathrm{M}=$ male; $\mathrm{F}=$ female

Table 6 Positive blood alcohol cases by sex, alcohol history, and blood alcohol concentration (BAC)

\begin{tabular}{llllll}
\hline & \multicolumn{5}{l}{ Alcohol concentration $(\mathrm{mg} / 100 \mathrm{ml})$} \\
\cline { 3 - 6 } Sex, alcohol history & BAC+ number & $50-149$ & $150-249$ & $250-349$ & $350+$ \\
\hline M, H+ & 61 & 17 & 22 & 13 & 9 \\
M, H- & 79 & 37 & 32 & 9 & 1 \\
F, H+ & 21 & 5 & 6 & 6 & 4 \\
F, H- & 30 & 16 & 7 & 6 & 1 \\
M+F, H+ & 82 & 22 & 28 & 19 & 13 \\
M+F, H- & 109 & 53 & 39 & 15 & 2 \\
Total & 191 & 75 & 67 & 34 & 15 \\
\hline
\end{tabular}

$\mathrm{M}=$ male $; \mathrm{F}=$ female $\mathrm{H}=$ history of alcohol abuse. determination that the death was causally related to the known alcohol habits of the deceased. In all other categories only a minority had histories of alcohol abuse. Those categorised as abusers of alcohol were represented in all but one category of death (unknown/obscure deaths in males), indicating that many true alcoholics die with their alcoholism rather than of it.

Table 5 shows that $39 \%$ of males and $34 \%$ of females with histories of alcohol abuse had alcohol present in their blood at necropsy at concentrations $\geq 50 \mathrm{mg} / 100 \mathrm{ml}$, compared with only $9 \%$ (male) and $6 \%$ (female) without histories of alcohol abuse. This emphasises the value of obtaining a history of alcohol habits in determining who to test and in interpreting the results. Table 6 shows that for those with a history of alcohol abuse, the blood alcohol concentrations were spread throughout the ranges, whereas for those without a history of alcohol abuse the concentrations tended to be distributed in the lower ranges. At high alcohol concentrations those with a history of alcohol abuse predominated.

Of the 220 individuals with histories of alcohol abuse, 219 had blood samples available; $137(62 \%)$ of these had alcohol concentrations of $<50 \mathrm{mg} / 100 \mathrm{ml}$. In 38 of these cases alcohol was mentioned in Part I of the death certificate (34 instances of chronic alcoholism). In an additional 15 cases alcohol was mentioned in Part II, showing that many deaths attributed to the effects of alcohol, either as the primary or contributory cause, were associated with blood alcohol levels considered insufficient to cause death. ${ }^{7-9}$ In one case of a female with a history of excess alcohol consumption, no blood sample was obtained but both vitreous and urine samples were available and contained alcohol at concentrations $\geq 50 \mathrm{mg} / 100 \mathrm{ml}$.

Eliciting a history of alcohol abuse may be difficult even with a confidential enquiry, as recently highlighted. ${ }^{10}$ It is notable that table 1 contains three cases where the cause of death was considered unascertained even though alcohol was present at levels within the range $168-238 \mathrm{mg} / 100 \mathrm{ml}$. These deaths were not attributed to the effects of the alcohol present, primarily because of the absence of a clear history of alcohol abuse, although in two of the cases there was uncorroborated anamnestic 
Table 7 Individuals (male and female) 60 years or older with positive blood alcohol by category of death and blood alcohol concentration, subdivided by alcohol history $(H)$. Percentages are relative to total deaths (positive and negative) in each category

\begin{tabular}{|c|c|c|c|c|c|c|c|c|c|c|}
\hline \multirow[b]{3}{*}{ Manner of death } & \multirow{2}{*}{\multicolumn{2}{|c|}{$\begin{array}{l}\text { Total } \\
\text { number }\end{array}$}} & \multirow{2}{*}{\multicolumn{2}{|c|}{$\begin{array}{l}\text { Percentage } \\
\text { of total } \\
\text { deaths }\end{array}$}} & \multicolumn{6}{|c|}{ Alcohol concentration $(\mathrm{mg} / 100 \mathrm{ml})$} \\
\hline & & & & & \multicolumn{2}{|c|}{$50-149$} & \multicolumn{2}{|c|}{$150-249$} & \multicolumn{2}{|c|}{$250+$} \\
\hline & $\mathrm{H+}$ & $H-$ & $\mathrm{H+}$ & $H-$ & $H+$ & $H-$ & $\overline{H+}$ & $H-$ & $H+$ & $H_{-}$ \\
\hline $\begin{array}{l}1 \text { - Natural (CVS) } \\
1 \text { - Natural }\end{array}$ & 10 & 11 & 1 & 1 & 4 & 6 & 5 & 4 & 1 & 1 \\
\hline (other) & 1 & 3 & 0 & 1 & 0 & 1 & 1 & 2 & 0 & 0 \\
\hline 2 - Accident & 7 & 4 & 3 & 2 & 1 & 3 & 2 & 1 & 4 & 0 \\
\hline 3 - Suicide & 3 & 3 & 2 & 2 & 1 & 2 & 1 & 1 & 1 & 0 \\
\hline $\begin{array}{l}4 \text { - Homicide } \\
5 \text { - Drug or }\end{array}$ & 0 & 0 & 0 & 0 & 0 & 0 & 0 & 0 & 0 & 0 \\
\hline $\begin{array}{l}\text { alcohol abuse } \\
6 \text { - Unknown/ }\end{array}$ & 3 & 4 & 4 & 5 & 1 & 1 & 1 & 0 & 1 & 3 \\
\hline obscure & 0 & 1 & 0 & 3 & 0 & 0 & 0 & 1 & 0 & 0 \\
\hline Total & 24 & 26 & 2 & 2 & 7 & 13 & 10 & 9 & 7 & 4 \\
\hline
\end{tabular}

CVS=cardiovascular system. abuse in determining the relative roles of the different pathologies found at necropsy in ascertaining the cause of death.

Our data correlate well with clinical studies, ${ }^{11-13}$ indicating that alcoholism in the elderly is underreported. Olsen-Noll and Bosworth classified elderly alcoholics into three groups: survivors (persistent heavy drinkers), intermittent drinkers (bingers), and reactors (began heavy drinking late in life). ${ }^{12}$ Using a history of alcohol consumption habits in combination with necropsy findings and alcohol assay, the diagnosis of survivors and intermittent drinkers in the forensic necropsy population should be comparatively easy. Reactors may escape diagnosis by virtue of an absence of a clear history of alcohol abuse and the relative paucity of alcohol related disease at necropsy and are likely to comprise those "hidden" alcoholics who would be detected only by universal necropsy alcohol assays. Appropriate certification of such deaths is difficult without routine alcohol testing. Consequently, a significant proportion of "hidden" alcoholics may be individuals aged 60 years or older.

Most necropsy alcohol research has concerned blood samples. Blood alcohol concentrations $>50 \mathrm{mg} / 100 \mathrm{ml}$ are likely to reflect antemortem consumption. There is still debate as to whether blood alcohol levels of $<50$ $\mathrm{mg} / 100 \mathrm{ml}$ reflect antemortem consumption or postmortem production. Analysis of other body fluids may assist in corroboration and interpretation of low blood alcohol concentrations. ${ }^{4}{ }^{14}$ Levine et al investigated low necropsy alcohol concentrations in blood, vitreous, and urine. ${ }^{6}$ Table 8 shows the equivalent data for our series. It is postulated that if any alcohol present results from putrefaction there will not be consistency throughout the body with regard to the presence of alcohol or to the levels detected. If, however, the analytical results represent the antemortem status of the deceased there should be alcohol present in all of the samples analysed at comparable concentrations. This problem is greatest at low blood alcohol levels. At high blood alcohol levels the contribution of putrefactive alcohol production to the total alcohol level detected is not likely to be significant. Where only a blood sample is taken, it is not possible to determine if any alcohol detected represents the antemortem alcohol intake of the deceased or is a postmortem artefact. The analysis of additional samples will permit confirmation of the presence and corroboration of the concentration of any alcohol detected in the blood. Where low levels of alcohol are present in the blood at necropsy, analysis of vitreous and urine will permit the separation of cases into three categories: vitreous and urine available and both positive (true positives); urine and/or vitreous available but at least one of these is negative (false positives); and unknowns, where either only one sample is available and contains alcohol or where neither urine nor vitreous is available to permit corroboration. Table 9 showed that, as the blood alcohol concentration rises, so corroboration of results in urine or vitreous, where available, became more fre- 
Table 8 Presence of alcohol in alternative samples (both sexes) at low blood alcohol levels. Urine and vitreous positive at $\geq 5 \mathrm{mg} / 100 \mathrm{ml}$. N/A indicates no sample available

\begin{tabular}{lllll}
\hline \multirow{4}{*}{$B A C(\mathrm{mg} / 100 \mathrm{ml})$} & \multicolumn{2}{l}{ Positivity of vitreous or urine } & & \\
\cline { 2 - 5 } & & Vitreous+ & N/A & Vitreous- \\
\hline $11-20$ & Urine+ & 11 & 4 & 1 \\
& N/A & 7 & 0 & 4 \\
& Urine- & 0 & 1 & 3 \\
$21-30$ & Urine+ & 5 & 1 & 3 \\
& N/A & 7 & 0 & 7 \\
& Urine- & 0 & 0 & 1 \\
$31-40$ & Urine+ & 8 & 3 & 0 \\
& N/A & 3 & 0 & 2 \\
$41-50$ & Urine- & 0 & 0 & 1 \\
& Urine+ & 6 & 1 & 0 \\
& N/A & 3 & 0 & 1 \\
& Urine- & 0 & 0 & 0
\end{tabular}

BAC $=$ blood alcohol concentration.

Table 9 True positives, false positives, and unknowns by corroboration of the blood alcohol by vitreous and/or urine at low blood alcohol levels (from table 8)

\begin{tabular}{llccc}
\hline \multirow{5}{*}{$B A C(\mathrm{mg} / 100 \mathrm{ml})$} & \multicolumn{4}{l}{ Corroboration by vitreous or urine } \\
\cline { 2 - 5 } & Total & True+ & False+ & Unknown \\
\hline $11-20$ & 31 & 11 & 9 & 11 \\
$21-30$ & 24 & 5 & 11 & 8 \\
$30-40$ & 17 & 8 & 3 & 6 \\
$41-50$ & 11 & 6 & 1 & 4 \\
\hline
\end{tabular}

$\mathrm{BAC}=$ blood alcohol concentration

quent. There were four cases of disparity between urine and vitreous alcohol concentrations at blood alcohol concentrations $<30$ $\mathrm{mg} / 100 \mathrm{ml}$. This may represent concentrations in the alternative samples bordering on the limits of detection or result from artefactual alcohol production in one or more of the sources. However, the trend for false positives to decrease with increasing blood alcohol concentrations can be seen, indicating that a blood alcohol of $\geq 50 \mathrm{mg} / 100 \mathrm{ml}$ can be attributed to antemortem consumption with reasonable confidence.

In 10 cases there were no blood samples, but both vitreous and urine samples were obtained (table 5). Of these, eight had no alcohol in the other samples, including two with histories of alcohol abuse. In two cases of severe trauma and exsanguination, vitreous and urine alcohol concentrations were $(\mathrm{mg} / 100 \mathrm{ml}) 160$ (vitreous), 199 (urine), and 136 (vitreous), 147 (urine), again indicating the value of alternative samples in medicolegal investigations.

There are no studies on the economic implications of routine alcohol testing in medicolegal investigations. Hansen and Simonsen included two cases where the police refused to finance toxicological analyses following the "privatisation" of the medicolegal service in Denmark in $1986 .{ }^{7}$ The cost-effectiveness of forensic alcohol assays is a significant issue for all agencies involved. In the United Kingdom the unit cost of a forensic blood alcohol assay is about $£ 15$. Approximately 15000 deaths come to medicolegal investigation in Scotland annually and the annual costs of routine testing would be of the order of $£ 220000$. In England and Wales approximately 130000 fatalities annually are subject to a coroner's necropsy and testing all cases would incur annual costs of about $£ 2$ million.
In this series of 1620 cases there were 316 cases in which alcohol was detected in the blood, and 191 had concentrations of $\geq 50$ $\mathrm{mg} / 100 \mathrm{ml}$. Thus the overall cost incurred for each positive alcohol test was approximately £77. If alcohol assays were performed in deaths which were not clearly natural or where there was a history of alcohol abuse- -667 cases $(41 \%)$ in our series - the costs of systematic alcohol testing in Scotland would be reduced by more than half compared with comprehensive testing. This would have yielded 165 positive cases, and missed 26 natural deaths with negative histories and alcohol concentrations of $\geq 50 \mathrm{mg} / 100 \mathrm{ml}$. There were 868 individuals aged 60 years or older, of whom 50 had blood alcohol concentrations of $\geq 50 \mathrm{mg} / 100 \mathrm{ml}$. Routine assays in the elderly would detect a significant alcohol level in approximately $5 \%$ of cases. Using a history of alcohol abuse in all age groups (220 cases) as a criterion for testing would have detected $37 \%$ of those with alcohol concentrations $\geq 50 \mathrm{mg} / 100 \mathrm{ml}$ ( 82 out of 220). This would, however, still miss "hidden" alcoholics, which in this study accounted for $0.4 \%$ (six cases).

\section{Conclusions}

The data confirm that unnatural death is closely associated with alcohol ingestion, the tendency being more marked in males than females, as noted in previous studies. Performing alcohol assays on all forensic necropsy cases is not practical. Similarly, routine alcohol assays in the elderly are not cost-effective. However, routine alcohol testing is costeffective in all unnatural deaths and in known alcoholics. The study highlights again the essential requirement for good anamnestic data collection in forensic investigations.

1 Penttila A, Karhunen PJ, Vuori E. Blood alcohol in sudden and unexpected deaths. Forensic Sci Int 1989;43:95-102.

2 Kubo S, Dankwarth G, Puschel K. Blood alcohol concentrations of sudden unexpected deaths and non natural deaths. Forensic Sci Int 1991;52:77-84.

3 Dunne FJ, Schipperheijn JAM. Alcohol and the elderly [editorial]. BMF 1989;198:1660-1.

4 Pounder DJ, Kuroda N. Vitreous alcohol is of limited value in predicting blood alcohol. Forensic Sci Int 1994;65:73-80.

5 Walls HJ, Brownlie AR. Blood alcohol levels abroad. In: Drink, driving and drugs, 2nd ed. London: Sweet and Maxwell, 1985.

6 Levine B, Smith ML, Smialek JE, Caplan YH. Interpretation of low post mortem concentrations of ethaInterpretation of low post mortem
nol. ₹ Forensic Sci 1993;38:663-7.

7 Hansen AU, Simonsen J. The manner and cause of death in a forensic series of chronic alcoholics. Forensic Sci Int 1991; 49:171-8.

8 Clark JC. Sudden death in the chronic alcoholic. Forensic $S c i$ Int 1988;36:105-11.

9 Girela AK, Lachica E, Pounder DJ. Death certification of problem drinkers. Med Sci Law 1992;32:233-6.

10 Shepherd RM, Dent THS, Alexander GJM, London $M$. Prevalence of alcohol histories in medical and nursing notes of patients admitted with self poisoning. $B M 71995$; 311:847.

11 Naik PC, Jones RG. Alcohol histories taken from elderly people on admission. BMF 1994;308:248.

12 Olsen-Noll CG, Bosworth MF. Alcohol abuse in the elderly. Am Fam Physician 1989;39:173-9.

13 Ticehurst S. Alcohol and the elderly. Aust NZ F Psychiatr 1990;24:252-60.

14 Heatley MK, Crane J. The relationship between blood and urine alcohol concentrations at autopsy. Med Sci Law 1989;29:209-17. 